\title{
TPX2 in human clear cell renal carcinoma: Expression, function and prognostic significance
}

\author{
QI CHEN, BIN CAO, NING NAN, YU WANG, XU ZHAI, YOUFANG LI and TIE CHONG
}

Department of Urology, The Second Affiliated Hospital of Xi'an Jiaotong University, Xi'an, Shaanxi 710004, P.R. China

Received December 4, 2014; Accepted January 15, 2016

DOI: $10.3892 / \mathrm{ol} .2016 .4396$

\begin{abstract}
Targeting protein for Xenopus kinesin-like protein 2 (TPX2) is a microtubule-associated protein. TPX2 is considered to be an important gene in tumorigenesis; however, the particular function of TPX2 in the development of human renal cell carcinoma (RCC) is unknown. In the present study, the expression, function and prognostic significance of TPX2 in human RCC was analyzed. A total of 286 tissue samples from patients with RCC who had undergone nephrectomies were utilized. Subsequently, the expression of TPX2 protein was investigated using immunohistochemistry and western blotting, and TPX2 mRNA expression was examined using reverse transcription-quantitative polymerase chain reaction. To establish the effect of TPX2 on the proliferation and invasion of the RCC cells, TPX2 expression was increased by stable transfection with a TPX2 vector and TPX2 expression was decreased using small interfering RNA. Proliferation of the RCC cells was analyzed using a WST-1 assay and an animal xenograft model with BALB/c nude mice, whilst invasion of the RCC cells was examined using a Matrigel-coated invasion chamber. It was demonstrated that TPX2 expression was significantly higher in the RCC tissues compared with normal kidney tissues $(\mathrm{P}<0.05)$. Furthermore, TPX2 expression was associated with tumor size, histological grade and tumor stage $(\mathrm{P}<0.05)$, and was observed to markedly increase the proliferation and invasion of the RCC cells. It may be concluded that the expression of TPX 2 is significantly upregulated in RCC tissue, subsequently increasing the proliferative and invasive ability of RCC cells. Therefore, the protein may serve as a therapeutic target and independent prognostic factor in the treatment of human RCC.
\end{abstract}

Correspondence to: Dr Tie Chong, Department of Urology, The Second Affiliated Hospital of Xi'an Jiaotong University, 157 West 5th Road, Xi'an, Shaanxi 710004, P.R. China

E-mail: tiechong898@163.com

Key words: renal cell carcinoma, targeting protein for Xenopus kinesin-like protein 2, prognosis

\section{Introduction}

Human renal cell carcinoma (RCC) is the most lethal urinary malignancy and consists of a number of different pathological types, including clear cell, chromophobe and papillary RCC, which all arise from the epithelium of the renal tubules $(1,2)$. The most prevalent RCC subtype is clear cell, accounting for $85 \%$ of all RCC cases (3). Generally, RCC is resistant to conventional radiotherapy and chemotherapy $(4,5)$. Prognosis for patients with metastatic RCC is poor, with a median survival time of 8 months and a 5 -year survival rate of $10 \%$ (6). Although certain genes have been investigated as potential prognostic predictors and therapeutic targets for RCC, the molecular mechanisms underlying the development and progression of RCC remain largely unknown.

Targeting protein for Xenopus kinesin-like protein 2 (TPX2) is a microtubule-associated protein, and functions to regulate the construction of the mitotic spindle by promoting microtubule nucleation from chromatin and stabilization of the spindle microtubules $(7,8)$. It has been demonstrated that TPX2 overexpression induces the amplification of centrosomes and results in DNA polyploidy (9). TPX2 also serves a crucial role in the proliferation of various tumor cells $(10,11)$. TPX2 expression is closely regulated by the cell cycle, and exhibits particularly high expression in proliferating cells transitioning between the $\mathrm{G}_{1}$ and $\mathrm{S}$ phase (12-14). Certain studies have demonstrated that the TPX2 gene, in addition to elevated gene copy numbers, is frequently identified in various human malignancies, including lung carcinoma (15), salivary gland cancer (16), esophageal cell carcinoma (17) and breast cancer (18). Furthermore, the upregulated expression of TPX2 has been observed in a number of different tumors, including bladder and colon cancer $(19,20)$. Such results have revealed the correlation between TPX 2 and the tumorigenesis of cancer. In addition, it has been demonstrated that the overexpression of TPX2 serves an important role in the progression and invasion of human malignancies (21), and that its expression is associated with the aggressiveness of ovarian cancer (22). Previous studies have reported that TPX 2 is involved in cell proliferation and associated with poor prognosis in patients with esophageal cell carcinoma $(23,24)$, supporting the hypothesis that TPX2 functions as a tumor promoter in this particular type of cancer.

When combined, the aforementioned reports suggest that TPX2 may be involved in the progression of malignant tumors; however, the function of TPX2 expression in human RCC 
remains unknown. Thus, the present study investigated the effect of TPX2 expression on the proliferation and invasion of RCC cells. The results indicated that the expression of TPX2 is upregulated in RCC, and that TPX2 provokes the invasion and proliferation of RCC cells through the suppression of Akt/mammalian target of rapamycin (mTOR) signaling. Such findings indicate that TPX2 may serve as an independent prognostic factor and a therapeutic target in human clear cell RCC.

\section{Materials and methods}

Patients and tissue specimens. Tissue samples from 286 patients with RCC were collected (36 patients succumbed to disease and 15 patients were lost to follow-up, therefore a total of 51 patients were not evaluated in the survival analysis), and all of the tumor samples were diagnosed as conventional clear cell RCC. Neoplasms were surgically resected in the Department of Urology, The Second Affiliated Hospital of Xi'an Jiaotong University (Xi'an, China) between January 2003 and May 2012. The study was approved by the Ethics Committee of The Second Affiliated Hospital of Xi'an Jiaotong University. The tumors were graded according to the criteria of the Fuhrman grading system of malignant tumors, and the clinical tumor stage was classified according to the tumor, node, metastasis classification system $(25,26)$. RCC specimens and corresponding normal healthy kidney tissues located as far as possible from the tumor were obtained. The samples were then fixed in formalin, dehydrated and embedded in paraffin. All the RCC specimens were frozen in liquid nitrogen subsequent to surgical resection, and were maintained at $-90^{\circ} \mathrm{C}$ for protein and mRNA extraction.

Cell culture. A total of 4 RCC cell lines (ACHN, Caki-1, Caki-2 and NC65) were obtained from the American Type Culture Collection (Manassas, VA, USA), and were cultured with complete medium composed of RPMI-1640 medium (Gibco; Thermo Fisher Scientific, Inc., Waltham, MA, USA), 2 mM L-glutamine, 1\% non-essential amino acids, $25 \mathrm{mM}$ HEPES, $10 \%$ fetal bovine serum (FBS), $100 \mathrm{U} / \mathrm{ml}$ penicillin and $100 \mu \mathrm{g} / \mathrm{ml}$ streptomycin (all purchased from Sigma-Aldrich, St. Louis, MO, USA). All RCC cell lines were maintained as monolayers in $10-\mathrm{cm}$ plastic dishes and were incubated in a humidified atmosphere containing $5 \% \mathrm{CO}_{2}$ at $37^{\circ} \mathrm{C}$.

Animal RCC xenograft experiments. A total of $30 \mathrm{BALB} / \mathrm{c}$ nude mice (age, 3-4 weeks) were kept in specific pathogen-free conditions at a temperature of $26-28^{\circ} \mathrm{C}$ and humidity of $30-40 \%$. The light/dark cycle was $12 \mathrm{~h}$, and food and water were supplied. The mice were randomly divided into the following two groups: TPX2 vector group and control group. The RCC cells $\left(4 \times 10^{7}\right)$ were seeded into the back region of each mouse via subcutaneous injection. All of the mice were observed, with observations recorded for 5 continuous weeks and the size of the xenograft measured once a week (calculated using the formula $v=a b^{2} \pi / 6$, where $a$ is the longest diameter and $b$ is the longest diameter perpendicular to the tumor). At 5 weeks post-injection, all mice were sacrificed under deep anesthesia via intraperitoneal injection with pentobarbital sodium (80 mg/kg; Roche Diagnostics GmbH, Penzberg, Germany) and the final size of each xenograft was recorded.
Immunohistochemistry (IHC). Following the replacement of paraffin with xylene the tissue samples were rehydrated via a graded alcohol series (Sigma-Aldrich). Endogenous peroxidase activity was quenched with $0.3 \%$ hydrogen peroxide (Sigma-Aldrich) for $15 \mathrm{~min}$, and the sections were blocked with $5 \%$ bovine serum albumin (Sigma-Aldrich) for $1 \mathrm{~h}$. The sections were then incubated at $37^{\circ} \mathrm{C}$ for $1 \mathrm{~h}$ with rabbit anti-human TPX2 polyclonal antibody (dilution, 1:1,000; catalog no. ab71816; Abcam, Cambridge, UK) diluted in phosphate-buffered saline. Following incubation at $37^{\circ} \mathrm{C}$ for $2 \mathrm{~h}$ with a biotinylated goat anti-rabbit immunoglobulins polyclonal secondary antibody (dilution, 1:2,000; catalog no. E0432; Dako, Glostrup, Denmark), all sections were treated with an avidin-biotin peroxidase complex (Dako). IHC staining was assessed, and the results were scored using a light microscope (BH-2; Olympus Corporation, Tokyo, Japan). The intensity of TPX2 immunostaining was semi-quantified using the following scale: -, negative; +, weak; ++ , moderate; and +++, strong staining.

Cell proliferation assay. Cell proliferation was analyzed using a WST-1 assay, with $2 \times 10^{3}$ exponentially-growing RCC cells seeded in a 96-well microtiter plate. Following continuous incubation for 1, 2 and 3 days, $10 \mu$ WST-1 (Roche Diagnostics $\mathrm{GmbH}$ ) was added to each well and the incubation was continued for an additional $1 \mathrm{~h}$. The absorbance, representing the RCC cell count in each well, was measured using a microculture plate reader (NJ-2000 Immunoreader; Intermed Japan Co., Ltd., Tokyo, Japan) at an optical density of $450 \mathrm{~nm}$.

Invasion assay. RCC cells $\left(2 \times 10^{4}\right)$ were harvested and seeded in the upper chamber of a 24-Multiwell BD FluoroBlok insert (8.0 $\mu \mathrm{m}$ pore size; BD Biosciences, Franklin Lakes, NJ, USA) with no-FBS medium (Gibco; Thermo Fisher Scientific, Inc.). The chemotaxis gradient was performed using medium containing $10 \%$ FBS in the lower chamber. Following a 24-h incubation, the RCC cells that had migrated to the lower chamber were stained with hematoxylin (Sigma-Aldrich) and counted using ImageJ software version 1.45 (www.imagej.nih. gov/ij; National Institutes of Health, Bethesda, MD, USA).

RNA isolation and reverse transcription-quantitative polymerase chain reaction $(R T-q P C R)$. RNA isolation was performed using TRIzol ${ }^{\circledR}$ reagent, according to the manufacturer's protocol (Invitrogen; Thermo Fisher Scientific, Inc.), and the total RNA was subjected to first-strand cDNA synthesis (Promega Corporation, Madison, WI, USA). All reagents used were from the GoScript ${ }^{\mathrm{TM}}$ Reverse Transcription system (Promega Corporation, Madison, WI, USA) RT-qPCR was performed using a Mastercycler ${ }^{\circledR}$ Nexus (Eppendorf, Hamburg, Germany) with an $\mathrm{IQ}^{\mathrm{TM}} \mathrm{SYBR}^{\circledR}$ Green Supermix kit (Bio-Rad Laboratories, Inc., Hercules, CA, USA). TPX2 was amplified using the following primers: Forward, 5'-AGG GGCCCTTTGAACTCTTA-3' and reverse, 5'-TGCTCTAAA CAAGCCCCATT-3'. GAPDH was used as an endogenous control with the following primers: Forward, 5'-ATCAAG AAGGTGGTGAAGCAGG-3' and reverse, 5'-GTGGAGGAG TGGGTGTCGC-3'. PCR was performed under the following conditions: Initial denaturation was performed at $95^{\circ} \mathrm{C}$ for $5 \mathrm{~min}$, followed by 35 cycles of $95^{\circ} \mathrm{C}$ for $30 \mathrm{sec}, 60^{\circ} \mathrm{C}$ for $30 \mathrm{sec}, 72^{\circ} \mathrm{C}$ for $1 \mathrm{~min}$, followed by a final extension step at 
$72^{\circ} \mathrm{C}$ for $10 \mathrm{~min}$. The PCR products were quantified using the LightCycler ${ }^{\circledR} 480$ Real-Time PCR system (Roche Diagnostics $\mathrm{GmbH}$ ) and TPX2 expression was normalized to GAPDH. Each RT-qPCR experiment was repeated three times.

Western blotting. Protein was isolated using lysis buffer (Abcam), and the total protein concentration was evaluated using the Quick Start ${ }^{\mathrm{TM}}$ Bradford Protein assay (Bio-Rad Laboratories, Inc.). Western blot analysis was performed by loading $50 \mu \mathrm{g}$ protein onto an $8 \%$ sodium dodecyl sulfate polyacrylamide gel for electrophoresis. The polyvinylidene fluoride membranes were blocked with $0.5 \%$ bovine serum albumin, then incubated with the rabbit anti-human TPX2 polyclonal antibody (catalog no., ab71816; dilution, 1:1,000; Abcam) at $37^{\circ} \mathrm{C}$ for $1 \mathrm{~h}$; a mouse anti-human $\beta$-actin monoclonal antibody (mAb; catalog no. ab6276; dilution, 1:5,000; Abcam) was also used as a loading control. Other antibodies used for western blotting were purchased from Cell Signaling Technology, Inc. (Danvers, MA, USA), as follows: Rabbit anti-human Akt (pan) (catalog no. 4685)/phosphorylated-Akt (p-Akt; Ser473) monoclonal antibody (mAb; catalog no. 4060); rabbit anti-human mTOR (catalog no. 2983)/p-mTOR (Ser2481) mAb (catalog no. 2974); and rabbit anti-human p70S6K (catalog no. 2708)/p-p70S6K (Thr421) rabbit mAb (catalog no. 9204). All antibodies were diluted at 1:2,000. The immune complexes were visualized using the Amersham ECL Prime Western Blotting Detection reagent (GE Healthcare Life Sciences, Chalfont, UK) and quantified using Image J software (online version; imagej.nih.gov/ij/; National Institutes of Health)

Small interfering RNA (siRNA) and transfection. siRNA oligonucleotide sequences for TPX2 were designed using siDirect software (www.sidirect2.rnai.jp). The sequences were as follows: Forward, 5'-CCAUUAACCUGCCAGAGAAT-3'; and reverse, 5'-UUCUCUGGCAGGUUAAUGGT-3'. The RCC cells were seeded into plastic culture dishes and incubated with complete medium without antibiotics until the cells reached $40 \%$ confluence. The cells were transfected with siRNA oligonucleotides using Lipofectamine ${ }^{\circledR} 2000$ (Invitrogen; Thermo Fisher Scientific, Inc.). Following continuous incubation at $37^{\circ} \mathrm{C}$ for 2 days, TPX2 expression was analyzed by western blotting. The cDNA of TPX 2 was cloned using the HK-2 normal human kidney cell line as a substrate, and the PCR products were subcloned into the pcDEF3 vector (Sigma-Aldrich). The RCC cell lines were stably transfected using Lipofectamine 2000 with the expression vector containing full-length TPX2 cDNA. The monoclonal cell line was selected using G418 (Sigma-Aldrich) and TPX2 expression, and evaluated by western blotting.

Statistical analysis. SPSS software (version 19.0; IBM SPSS, Armonk, NY, USA) was used for statistical analysis. All data are expressed as the mean \pm standard deviation. Comparisons between groups were made using Student's t-test, and the $\chi^{2}$ test was used to analyze the association between TPX2 expression and the clinicopathological parameters. A total of 51 patients succumbed to the disease or were lost to follow up and thus survival could only be analyzed in 235 patients. Survival curves were estimated by Kaplan-Meier analysis. All experiments were performed in triplicate, and a $\mathrm{P}<0.05$ was considered to indicate a statistically significant difference.

\section{Results}

Patient characteristics. The study enrolled 192 males (61.1 \pm 16.3 years) and 94 females ( $62.5 \pm 17.4$ years). The tumor diameter range was 3.8-14.7 cm (median size, $6.9 \mathrm{~cm}$ ). Tumor grading identified 124, 97 and 65 patients with Fuhrman grades 1, 2 and 3, respectively. Tumor staging identified 147, 73,51 and 25 patients with cancer stages I, II, III and IV, respectively. RCC was an incidental finding during routine examination in 209 patients. The presenting symptoms for RCC included flank pain (33 patients), a palpable mass (21 patients) and hematuria (21 patients). Laboratory examination detected an increased sedimentation rate in 42 patients, anemia in 31 patients, thrombocytopenia in 14 patients and erythrocytosis in 7 patients. A total of 49 patients had one or more complicated diseases, including urolithiasis, angina pectoris, valvular heart disease and diabetes mellitus. In addition, 10 patients had previously undergone radical nephrectomies and 25 patients had metastatic disease at the time of diagnosis.

TPX2 protein expression in RCC tissue. TPX2 protein expression was examined in the human RCC and normal kidney tissue samples by IHC and RT-qPCR. Generally, it was observed that TPX2 was overexpressed in the RCC tissues when compared with the corresponding normal kidney tissues. TPX2 expression was detected in 262/286 patients with RCC (91.6\%). By contrast, TPX2 expression was detected in 130/286 normal kidney tissues (36.3\%). Regarding the association between TPX2 expression and clinicopathological parameters in RCC, $\chi^{2}$ testing determined that TPX2 expression was significantly increased in advanced tumor stages, higher histological grades and tumors $>7 \mathrm{~cm}$ in size $(\mathrm{P}<0.05)$. None of the other parameters, including gender and age, demonstrated a significant association with TPX2 expression (Table I). RT-qPCR was also used to assess TPX2 expression in the human RCC and normal kidney tissues. The relative level of TPX2 expression was determined with reference to GAPDH. TPX2 was significantly overexpressed in the RCC tissues when compared with the corresponding normal kidney tissues. Similar expression levels were detected by IHC (Table I). These findings suggest that TPX2 may function in the carcinogenesis and progression of human RCC.

TPX2 increases the proliferation of RCC cells. TPX2 expression was increased using an expression vector containing full-length TPX2 cDNA. The vector was stably transfected into the ACHN, Caki-1, Caki-2 and NC65 cell lines. TPX2 expression was also decreased using siRNA. Following transfection, all experiments were evaluated by western blotting. It was observed that TPX 2 expression was markedly upregulated by the TPX 2 vector and downregulated by the siRNA compared with the control (Fig. 1A). The effect of TPX2 expression on the proliferation of the RCC cells in vitro was investigated using a WST-1 assay, which indicated that the RCC cells expressing high levels of TPX2 had markedly increased proliferation when compared with the untreated control cells. The RCC cells with low TPX2 expression had a significantly reduced proliferative 

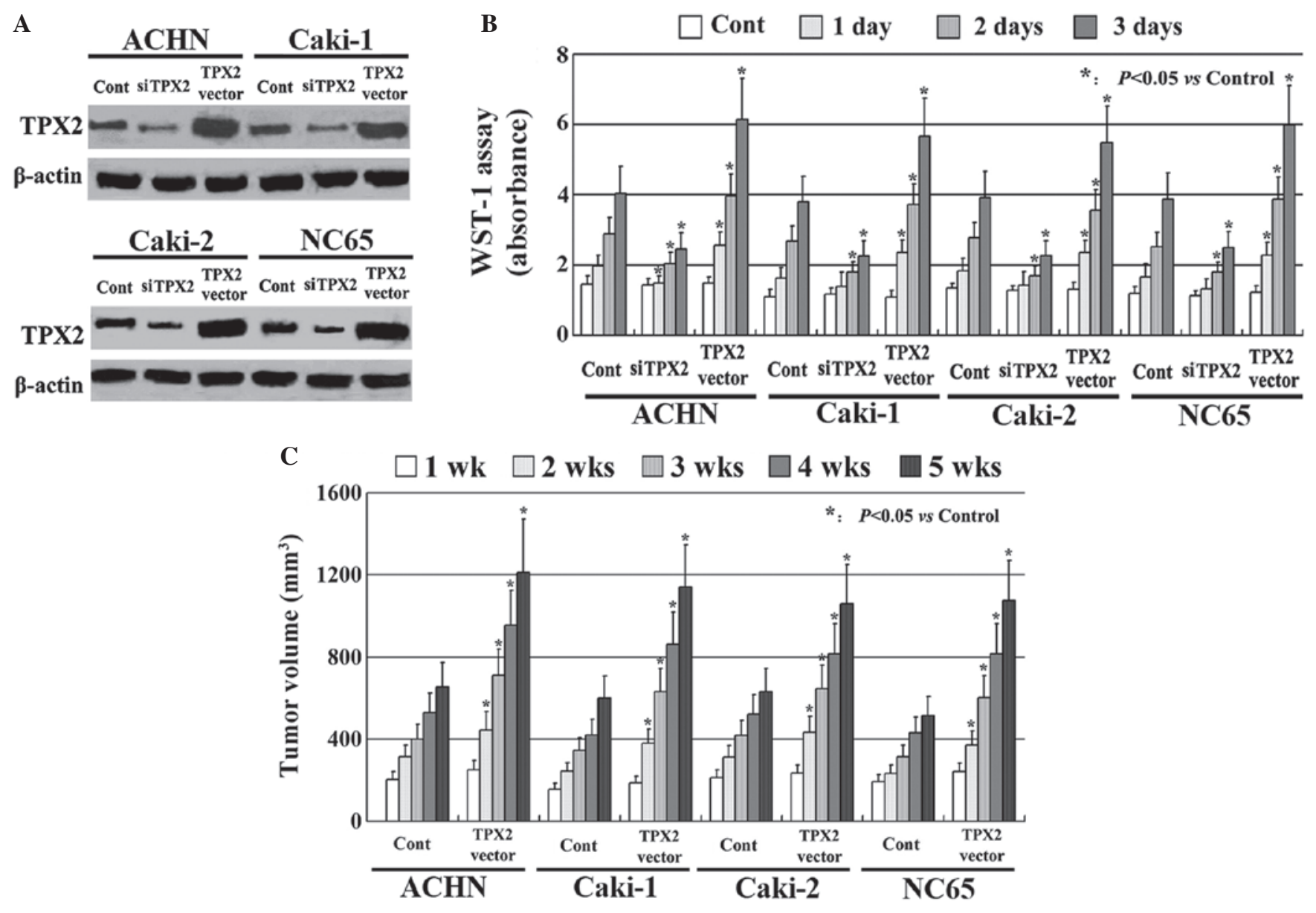

Figure 1. Effect of TPX2 on the proliferation of the renal cell carcinoma (RCC) cells. The expression vector for TPX2 or siRNA oligonucleotide were transfected into the four RCC cell lines. (A) Transfection was evaluated by western blotting; (B) proliferative ability of the RCC cells was analyzed by WST-1 assay; and (C) tumor growth was evaluated in an animal xenograft model. Cont, control; si, small interfering; TPX2, targeting protein for Xenopus kinesin-like protein 2; wk/s, week/s.

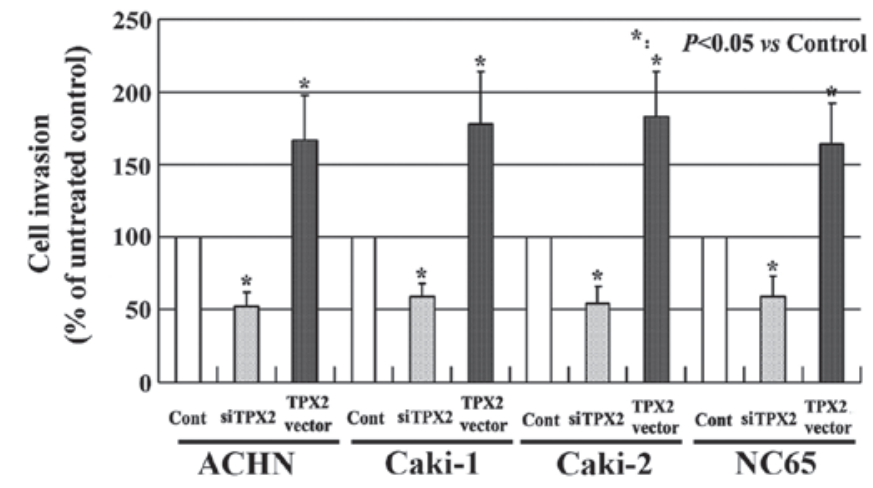

Figure 2. Effect of TPX2 expression on the invasive ability of human renal cell carcinoma cells. si, small interfering; TPX2, targeting protein for Xenopus kinesin-like protein 2.

ability (Fig. 1B; $\mathrm{P}<0.05)$. Similar results were confirmed by the animal xenograft model $(\mathrm{P}<0.05$; Fig. $1 \mathrm{C} ; \mathrm{P}<0.05)$.

TPX2 increases the invasion of RCC cells. The effects of TPX2 on the invasion of the RCC cells was also evaluated. As presented in Fig. 2, the RCC cells with high TPX2 expression exhibited a higher level of invasion when compared with the untreated cells $(\mathrm{P}<0.05)$. By contrast, the RCC cells with low TPX2 expression had a markedly reduced invasive ability compared with the untreated controls $(\mathrm{P}<0.05)$. These results indicate that TPX2 enhances the invasion of the RCC cells and that TPX2 may serve a crucial role in RCC progression.

TPX2 increases phosphoinositide 3-kinase (PI3K)/mTOR activity in RCC cells. To clarify how the Akt/mTOR pathway is involved in TPX2-induced proliferation and invasion, phosphorylation of the Akt/mTOR pathway was analyzed. TPX2 expression was upregulated by transfection with the pcDEF3 vector containing the full length TPX2 cDNA, and TPX2 expression was downregulated using siRNA. In the ACHN and NC65 cell lines, despite TPX2 expression having no affect on the expression of the Akt and mTOR/p70S6K proteins, the increased expression of TPX2 upregulated the phosphorylation of Akt and mTOR/p70S6K compared with the control, as observed by western blotting. By contrast, decreased expression of TPX2 downregulated the phosphorylation of Akt and mTOR/p70S6K compared with the control (Fig. 3). These findings indicate that the Akt/mTOR pathway is regulated by TPX2, and may therefore serve a key role in TPX2-induced proliferation and invasion of RCC cells.

Prognostic significance of TPX2 expression. As a correlation was identified between TPX2 expression, and RCC stage and 
Table I. Characteristics of 286 patients with RCC, including TPX2 expression detected by reverse transcription-quantitative polymerase chain reaction and immunohistochemistry.

TPX2 protein expression, $\mathrm{n}$

\begin{tabular}{|c|c|c|c|c|c|c|c|c|}
\hline Characteristic & Patients, $\mathrm{n}$ & TPX2 mRNA expression ${ }^{\mathrm{a}}$ & P-value & - & + & ++ & +++ & P-value \\
\hline $\mathrm{RCC}$ & 286 & $3.31 \pm 0.34$ & & 24 & 61 & 112 & 89 & \\
\hline Healthy kidney & 286 & $0.89 \pm 0.15$ & $<0.05$ & 156 & 97 & 33 & 0 & $<0.05$ \\
\hline \multicolumn{9}{|l|}{ Gender } \\
\hline Male & 192 & $3.34 \pm 0.35$ & & 16 & 42 & 74 & 60 & \\
\hline Female & 94 & $3.23 \pm 0.39$ & $>0.05$ & 8 & 19 & 38 & 29 & $>0.05$ \\
\hline \multicolumn{9}{|l|}{ Age, years } \\
\hline$<60$ & 159 & $3.34 \pm 0.33$ & & 13 & 34 & 62 & 50 & \\
\hline$\geq 60$ & 127 & $3.26 \pm 0.44$ & $>0.05$ & 11 & 27 & 50 & 39 & $>0.05$ \\
\hline \multicolumn{9}{|c|}{ Tumor diameter, $\mathrm{cm}$} \\
\hline$\leq 7$ & 147 & $2.59 \pm 0.21$ & & 18 & 53 & 50 & 26 & \\
\hline$>7$ & 139 & $4.06 \pm 0.32$ & $<0.05$ & 6 & 8 & 62 & 63 & $<0.05$ \\
\hline \multicolumn{9}{|c|}{ Histological grade } \\
\hline G1 & 124 & $2.31 \pm 0.15$ & & 21 & 42 & 59 & 2 & \\
\hline $\mathrm{G} 2$ & 97 & $3.45 \pm 0.37$ & & 3 & 17 & 35 & 42 & \\
\hline G3 & 65 & $4.98 \pm 0.46$ & $<0.05$ & 0 & 2 & 18 & 45 & $<0.05$ \\
\hline \multicolumn{9}{|l|}{ Clinical stage } \\
\hline I & 147 & $2.59 \pm 0.21$ & & 18 & 53 & 50 & 26 & \\
\hline II & 73 & $3.43 \pm 0.22$ & & 6 & 7 & 38 & 22 & \\
\hline III & 41 & $4.34 \pm 0.37$ & & 0 & 1 & 17 & 23 & \\
\hline IV & 25 & $5.44 \pm 0.48$ & $<0.05$ & 0 & 0 & 7 & 18 & $<0.05$ \\
\hline
\end{tabular}

a Data are presented as mean \pm standard deviation. -, negative; +, weak; ++, moderate; and +++, strong TPX2 protein expression. RCC, renal cell carcinoma; TPX2, targeting protein for Xenopus kinesin-like protein 2.

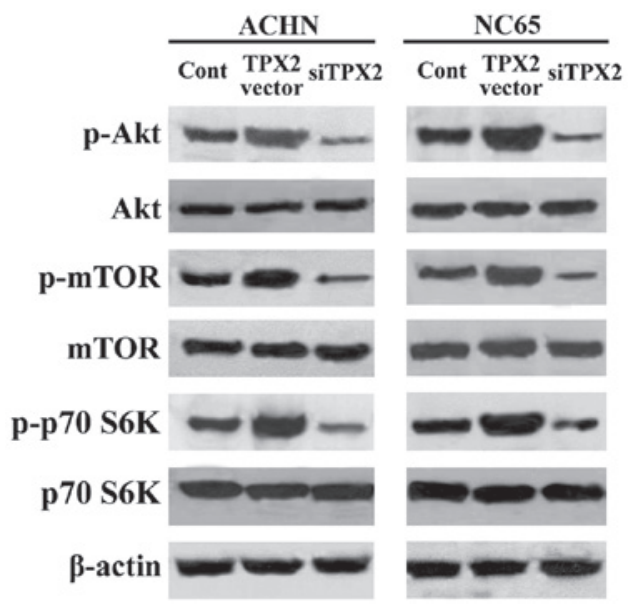

Figure 3. Western blot analysis demonstrating that TPX2 increased the activity of the Akt/mTOR pathway in renal cell carcinoma (RCC) cells. In the ACHN and NC65 cell lines, although TPX2 did not affect the protein expression of Akt and mTOR/p70S6K, high expression of TPX2 increased the phosphorylation of the components in the Akt/mTOR pathway. TPX2, targeting protein for Xenopus kinesin-like protein 2; si, small interfering; p-, phosphorylated; mTOR, mammalian target of rapamycin.

grade, it was then investigated whether or not TPX2 functions as a prognostic factor in human RCC. Kaplan-Meier analysis was performed to calculate the correlation between

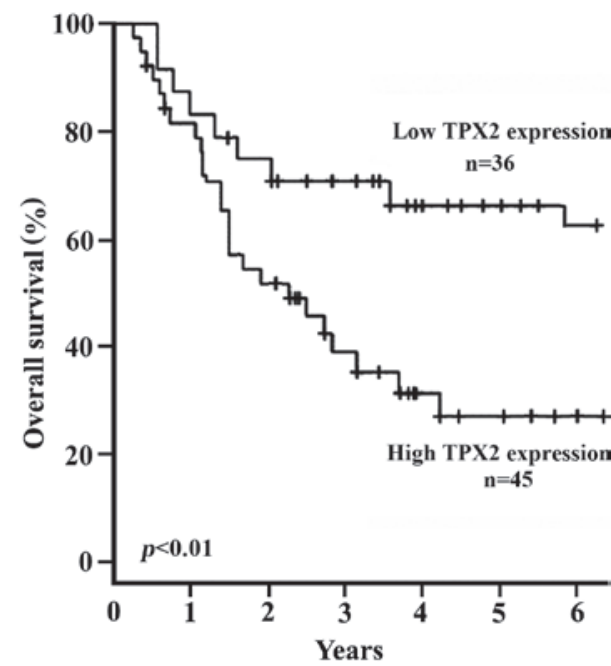

Figure 4. Kaplan-Meier analysis investigating the correlation between TPX2 expression and overall survival time of patients with human renal cell carcinoma. (RCC). High TPX2 expression was associated with poor prognosis and TPX2 expression was an independent factor for predicting the prognosis of human RCC. TPX2, targeting protein for Xenopus kinesin-like protein 2.

TPX2 expression and the survival time of patients with RCC (Fig. 4). A total of 19 patients succumbed to a myocardial infarction, 17 patients succumbed to disseminated malignant 
disease and 15 patients were lost to follow-up. The results also demonstrated that the survival time was significantly different between the high and the low TPX2 expression group ( $\mathrm{P}<0.01$ for time points from 2-6 years). After 6 years of follow-up, 36/56 patients $(64.3 \%)$ who had low TPX2 expression (IHC, - and +), were alive and disease-free compared with 45/179 patients (25.1\%) with high TPX2 expression (IHC, ++ and +++; Fig. 4). These results indicate that TPX2 may function as an independent factor in predicting the prognosis of human RCC.

\section{Discussion}

TPX2 was initially reported to be a Xenopus microtubule-associated protein (27). TPX2 is a cell cycle protein and serves a key role in the stability of the mitotic spindle (18). As a microtubule-associated protein, TPX2 tightly adheres to the mitotic spindle in mitotic cells (28). In certain tumors, overexpression of TPX 2 results in centrosome amplification and heteroploidy formation (29,30). TPX2 has been demonstrated to be upregulated in salivary gland carcinoma, lung carcinoma and ovarian cancer, with its abnormal expression involved in tumorigenesis and malignant progression $(15,16,31)$. Furthermore, overexpression of TPX2 can suppress the completion of mitosis and disturb the physiological activation of its own channels (32).

Matrix metalloproteases (MMPs) are known to degrade the components of the extracellular matrix, and are also particularly important for tumor invasion and metastasis (33). A previous study reported that TPX2 upregulates MMP levels by activating Akt signaling in colon cancer (20). Akt is a prominent serine/threonine kinase that affects important cellular processes by regulating its downstream effectors $(34,35)$; however, it remains unclear whether high levels of TPX2 expression enhances the proliferation and invasion of RCC cells by activating Akt signaling. Recently, gene target therapy has been the primary focus of research in the treatment of malignant tumors $(36,37)$. Thus, the investigation of novel gene therapy methods for RCC is important.

In the current study, the expression of TPX 2 in human RCC tissue was analyzed. The IHC results indicated that TPX2 expression was significantly upregulated in the RCC tissues compared with the normal kidney tissues. Furthermore, TPX2 expression was significantly associated with clinical stage, histological grade and tumor volume. In addition, the expression of TPX 2 in the RCC tissues was examined by RT-qPCR; this demonstrated consistent data to that produced by IHC, suggesting that TPX2 serves an important role in tumorigenesis and is a key gene in the progression of RCC. The effect of TPX 2 on the proliferation and invasion of the RCC cells was also evaluated. The results indicated that TPX2 significantly increased the proliferative ability of the RCC cells in vitro. The same results were observed in vivo in the animal xenograft model with BALB/c nude mice. Additionally, high expression levels of TPX2 significantly increased the invasive ability of the RCC cells.

A previous study by Engelman et al (38) reported that TPX2 can stimulate Akt signaling. Akt is a target protein of PI3K and phosphorylates several downstream mediators to enhance cell proliferation and survival (38). Akt activity can also regulate the phosphorylation of mTOR. It has been reported that p-mTOR and p-S6 are strongly coexpressed in RCC (39), and that p-mTOR increases the phosphorylation of p70S6K/S6, subsequently enhancing cell proliferation (40). An inhibitor of mTOR has been regarded as a novel therapeutic target for advanced RCC $(41,42)$. Despite the present study investigating TPX2 expression and its functions in RCC, the underlying molecular mechanism of TPX2 in RCC remains unclear. The results of the present study indicated that despite TPX2 not altering the protein expression of components in the Akt/mTOR pathway, TPX2 increased the phosphorylation of $\mathrm{Akt} / \mathrm{mTOR} / \mathrm{p} 70 \mathrm{~S} 6 \mathrm{~K}$ in the RCC cells. These findings suggest that the Akt/mTOR pathway is a potential target of TPX2, and serves a key role in TPX2-induced proliferation and invasion of RCC cells.

In the current study, the association between TPX2 expression and the survival time of patients with RCC was evaluated by Kaplan-Meier analysis. The results demonstrated that low TPX2 expression may be regarded as a valuable indicator of positive prognosis. Thus, TPX2 may function as an independent factor for predicting prognosis, aiding the follow-up of patients with RCC. TPX2 serves an important function in tumorigenesis of the kidney and the overexpression of TPX2 can promote the progression of RCC. Thus, it is possible that patients with RCC exhibiting high TPX2 expression may be vulnerable to RCC morbidities, with TPX2 serving as a prognostic factor. However, further investigation of the detailed TPX2 molecular mechanisms underlying human RCC should be performed.

In conclusion, the present study demonstrated that TPX2 is overexpressed in human RCC tissue, and can increase the proliferation and invasion of RCC cells. This indicates that TPX2 has an important function in the tumorigenesis and progression of human RCC, with the silencing of TPX2 expression possibly serving as a novel treatment strategy in the future.

\section{References}

1. Arai E and Kanai Y: Genetic and epigenetic alterations during renal carcinogenesis. Int J Clin Exp Pathol 4: 58-73, 2010.

2. Gupta K, Miller JD, Li JZ, Russell MW and Charbonneau C: Epidemiologic and socioeconomic burden of metastatic renal cell carcinoma (mRCC): A literature rereview. Cancer Treat Rev 34: 193-205, 2008.

3. Deng FM and Melamed J: Histologic variants of renal cell carcinoma: Does tumor type influence outcome? Urol Clin North Am 39: 119-132, 2012.

4. Hartmann JT and Bokemeyer C: Chemotherapy for renal cell carcinoma. Anticancer Res 19 (2C): 1541-1543, 1999.

5. Yu DS, Chang SY and Ma CP: The expression of mdr-1-related gp-170 and its correlation with anthracycline resistance in renal cell carcinoma cell lines and multidrug-resistant sublines. Br J Urol 82: 544-547, 1998.

6. Lin JA, Fang SU, Su CL, Hsiao CJ, Chang CC, Lin YF and Cheng CW: Silencing glucose-regulated protein 78 induced renal cell carcinoma cell line G1 cell-cycle arrest and resistance to conventional chemotherapy. Urol Oncol 32: 29.e1-29.e11, 2014.

7. Vos JW, Pieuchot L, Evrard JL, Janski N, Bergdoll M, de Ronde D, Perez LH, Sardon T, Vernos I and Schmit AC: The plant TPX2 protein regulates prospindle assembly before nuclear envelope breakdown. Plant Cell 20: 2783-2797, 2008.

8. Trieselmann N, Armstrong S, Rauw J and Wilde A: Ran modulates spindle assembly by regulating a subset of TPX2 and Kid activities including Aurora-A activation. J Cell Sci 116: 4791-4798, 2003. 
9. Gruss OJ, Wittmann M, Yokoyama H, Pepperkok R, Kufer T, Silljé H, Karsenti E, Mattaj IW and Vernos I: Chromosome induced microtubule assembly mediated by TPX2 is required for spindle formation in HeLa cells. Nat Cell Biol 4: 871-879, 2002.

10. Anderson MR, Harrison R, Atherfold PA, Campbell MJ, Darnton SJ, Obszynska J and Jankowski JA: Met receptor signaling: A key effector in esophageal adenocarcinoma. Clin Cancer Res 12: 5936-5943, 2006.

11. Kan T, Sato F, Ito T, Matsumura N, David S, Cheng Y, Agarwal R, Paun BC, Jin Z, Olaru AV, et al: The miR-106b-25 polycistron, activated by genomic amplification, functions as an oncogene by suppressing p21 and Bim. Gastroenterology 136: 1689-1700, 2009.

12. Tonon G, Wong KK, Maulik G, Brennan C, Feng B, Zhang Y, Khatry DB, Protopopov A, You MJ, Aguirre AJ, et al: High-resolution genomic profiles of human lung cancer. Proc Natl Acad Sci USA 102: 9625-9630, 2005.

13. Gruss OJ, Wittmann M, Yokoyama H, Pepperkok R, Kufer T, Silljé H, Karsenti E, Mattaj IW and Vernos I: Chromosome-induced microtubule assembly mediated by TPX2 is required for spindle formation in HeLa cells. Nat Cell Biol 4 : 871-879, 2002

14. Kufer TA, Silljé HH, Körner R, Gruss OJ, Meraldi P and Nigg EA: Human TPX 2 is required for targeting Aurora-A kinase to the spindle. J Cell Biol 158: 617-623, 2002.

15. Lin DM, Ma Y, Xiao T, Guo SP, Han NJ, Su K, Yi SZ, Fang J, Cheng SJ and Gao YN: TPX2 expression and its significance in squamous cell carcinoma of lung. Zhonghua Bing Li Xue Za Zhi 35: 540-544, 2006 (In Chinese).

16. Shigeishi H, Ohta K, Hiraoka M, Fujimoto S, Minami M, Higashikawa $\mathrm{K}$ and Kamata N: Expression of TPX2 in salivary gland carcinomas. Oncol Rep 21: 341-344, 2009.

17. Liu HC, Li YY, Liu YH and Liu HY: Expression of TPX2 mRNA and its correlation with clinical pathology in esophageal cancer. J Clin Exp Pathol 26: 151-153, 2010.

18. Colak D, Nofal A, Albakheet A, Nirmal M, Jeprel H, Eldali A, Al-Tweigeri T, Tulbah A, Ajarim D, Malik OA, et al: Age-specific gene expression signatures for breast tumors and cross-species conserved potential cancer progression markers in young women. PLoS One 8: e63204, 2013.

19. Yan L, Li S, Xu C,Zhao X, Hao B, Li H and Qiao B: Target protein for Xklp2 (TPX2), a microtubule-related protein, contributes to malignant phenotype in bladder carcinoma. Tumour Biol 34: 4089-4100, 2013

20. Wei P, Zhang N, Xu Y, Li X, Shi D, Wang Y, Li D and Cai S: TPX2 is a novel prognostic marker for the growth and metastasis of colon cancer. J Transl Med 11: 313, 2013.

21. El-Serag HB, Davila JA, Petersen NJ and McGlynn KA: The continuing increase in the incidence of hepatocellular carcinoma in the United States: An update. Ann Intern Med 139: 817-823, 2003.

22. Cáceres-Gorriti KY, Carmona E, Barrès V, Rahimi K, Létourneau IJ, Tonin PN, Provencher D and Mes-Masson AM: RAN nucleo-cytoplasmic transport and mitotic spindle assembly partners XPO7 and TPX2 are new prognostic biomarkers in serous epithelial ovarian cancer. PLoS One 9: e91000, 2014.

23. Liu HC, Zhang Y, Wang XL, Qin WS, Liu YH, Zhang L and Zhu CL: Upregulation of the TPX2 gene is associated with enhanced tumor malignance of esophageal squamous cell carcinoma. Biomed Pharmacother 67: 751-755, 2013

24. Liu HC, Liu YH, Li SL, Gao DL, Zhang L, Pang X, Zheng XY and Zhang YH: Expression of TPX2 and Aurora A in esophageal squamous carcinoma and their significance in clinical pathology. Cancer Res Prev Treat 36: 932-935, 2009.
25. Elmore JM, Kadesky KT, Koeneman KS and Sagalowsky AI: Reassessment of the 1997 TNM classification system for renal cell carcinoma. Cancer 98: 2329-2234, 2003.

26. Hong SK, Jeong CW, Park JH, Kim HS, Kwak C, Choe G, Kim HH and Lee SE: Application of simplified Fuhrman grading system in clear-cell renal cell carcinoma. BJU Int 107:409-415, 2011.

27. Shigeishi H, Fujimoto S, Hiraoka M, Ono S, Taki M, Ohta K, Higashikawa $\mathrm{K}$ and Kamata $\mathrm{N}$ : Overexpression of the receptor for hyaluronan-mediated motility, correlates with expression of microtubule-associated protein in human oral squamous cell carcinomas. Int J Oncol 34: 1565-1571, 2009.

28. Pascreau G, Eckerdt F, Lewellyn AL, Prigent C and Maller JL: Phosphorylation of p53 is regulated by TPX2-Aurora A in xenopus oocytes. J Biol Chem 284: 5497-5505, 2009.

29. Stewart S and Fang G: Anaphase-promoting complex/cyclosome controls the stability of TPX2 during mitotic exit. Mol Cell Biol 25: 10516-10527, 2005.

30. Ozlü N, Srayko M, Kinoshita K, Habermann B, O'toole ET, Müller-Reichert T, Schmalz N, Desai A and Hyman AA: An essential function of the C. elegans ortholog of TPX2 is to localize activated aurora A kinase to mitotic spindles. Dev Cell 9: 237-248, 2005

31. Scharer CD, Laycock N, Osunkoya AO, Logani S, McDonald JF, Benigno BB and Moreno CS: Aurora kinase inhibitors synergize with paclitaxel to induce apoptosis in ovarian cancer cells. J Transl Med 6: 79, 2008.

32. Gao J, Ding F, Liu Q and Yao Y: Knockdown of MACC expression suppressed hepatocellular carcinoma cell migration and invasion and inhibited expression of MMP2 and MMP9. Mol Cell Biochem 376: 21-32, 2013.

33. Crane R, Gadea B, Littlepage L, Wu H, Ruderman JV and Aurora A, meiosis and mitosis. Biol Cell 96: 215-229, 2004.

34. Leng J, Han C, Demetris AJ, Michalopoulos GK and Wu T: Cyclooxygenase-2 promotes hepatocellular carcinoma cell growth through Akt activation: Evidence for Akt inhibition in celecoxib induced apoptosis. Hepatology 38: 756-768, 2003.

35. Wang YH, Dong YY, Wang WM, Xie XY, Wang ZM, Chen RX, Chen J, Gao DM, Cui JF and Ren ZG: Vascular endothelial cells facilitated HCC invasion and metastasis through the Akt and $\mathrm{NF}-\kappa \mathrm{B}$ pathways induced by paracrine cytokines. J Exp Clin Cancer Res 32: 51, 2013.

36. Matsubara N, Mukai H, Naito Y, Itoh K, Komai Y and Sakai Y: First experience of active surveillance before systemic target therapy in patients with metastaticrenal cell carcinoma. Urology 82: 118-123, 2013.

37. Waalkes S, Kramer M, Herrmann TR, Schrader AJ, Kuczyk MA and Merseburger AS: Present state of target therapy for disseminated renal cell carcinoma. Immunotherapy 2: 393-398, 2010.

38. Engelman JA, Luo J and Cantley LC: The evolution of phosphatidylinositol 3-kinases as regulators of growth and metabolism. Nat Rev Genet 7: 606-619, 2006

39. Robb VA, Karbowniczek M, Klein-Szanto AJ and Henske EP: Activation of the mTOR signaling pathway in renal clear cell carcinoma. J Urol 177: 346-352, 2007.

40. Manning BD and Cantley LC: United at last: The tuberous sclerosis complex gene products connect the phosphoinositide 3-kinase/Akt pathway to mammalian target of rapamycin (mTOR) signalling. Biochem Soc Trans 31: 573-578, 2003.

41. Dasanu CA, Clark BA III and Alexandrescu DT: mTOR-blocking agents in advanced renal cancer: An emerging therapeutic option. Expert Opin Investig Drugs 18: 175-187, 2009.

42. Hudes GR: mTOR as a target for therapy of renal cancer. Clin Adv Hematol Oncol 5: 772-774, 2007. 